\title{
Recent advances in transarterial embolotherapies in the treatment of hepatocellular carcinoma
}

\author{
Edward Wolfgang Lee ${ }^{1,2}$, Sarah Khan ${ }^{1}$ \\ 'Division of Interventional Radiology, Department of Radiology, UCLA Medical Center, David Geffen School of Medicine at UCLA; ${ }^{2}$ UCLA \\ Pfleger Liver Institute, UCLA Medical Center, Los Angeles, CA, USA
}

Management of hepatocellular carcinoma (HCC) can be maximized with the utilization of multiple treatment modalities including transplant, surgical resection and locoregional therapies including ablative therapies and transarterial embolotherapies. Although transplant and surgical resection offer the best clinical outcomes, a limited number of patients are amenable to these surgical treatment options due to the advanced disease at presentation. Transarterial embolotherapies including conventional transarterial chemoembolization (CTACE), bland transarterial embolization (TAE), drug-eluting beads transarterial chemoembolization (DEB-TACE) and selective internal radiation therapy (SIRT) with Yttrium $90\left({ }^{90} \mathrm{Y}\right.$ ) have played an increasingly important role for these patients with unresectable HCC. With a better understanding of different transarterial embolotherapies, more personalized and precise treatment should be implemented for these patients with unresectable HCC. In this review, the updated evidence on the current role of each embolotherapy in the treatment of HCC is summarized. (Clin Mol Hepatol 2017;23:265-272)

Keywords: Hepatocellular carcinoma; Transarterial chemoembolization; Bland embolization; Selective internal radiation therapy; Yttrium-90; Radioembolization

\section{INTRODUCTION}

Hepatocellular carcinoma (HCC) is the second leading cause of cancer related deaths and accounts for $65 \%$ of all liver cancers. ${ }^{1-3}$ The SEER-Medicare database estimated a significant annual economic burden from HCC between 1991 and 1999 of 454.9 million US dollars. ${ }^{4}$ Surprisingly, the incidence of HCC has increased from $1.4 / 100,000$ cases between $1976-1980$ to $6.2 / 100,000$ cases in 2011. ${ }^{3}$ The increased incidence of HCC in the United States has promoted the use of catheter based, image guided therapies, including trans arterial chemoembolization (TACE) with convention- al trans-arterial chemotherapy or specifically doxorubicin (CTACE), using drug-eluting beads with chemotherapeutic agents (DEBTACE), bland embolization (TAE) and radioembolization or selective internal radiation therapy (SIRT) with Yttrium $90\left({ }^{90} \mathrm{Y}\right)$ microspheres. Loco-regional techniques reduce patient morbidity, reduce mortality, can be used repeatedly and are associated with increased survival. ${ }^{5}$ Advancement of these techniques and development of other novel approaches to disease management remain the focus of current laboratory based and clinical research.

Liver transplantation and resection are the only curative options for patients with HCC or colorectal cancer metastases, limited pri-

\footnotetext{
Abbreviations:

${ }^{90}$ Y, Yttrium 90; Ctace, conventional trans-arterial chemoembolization; DEB-TACE, Drug-Eluting Beads Chemoembolization; HCC, Hepatocellular carcinoma; PVA, polyvinyl alcohol; SIRT, selective internal radiation therapy; TACE, trans arterial chemoembolization; TAE, Transarterial Embolization
}

\section{Corresponding author : Edward Wolfgang Lee}

Division of Interventional Radiology, Department of Radiology, Ronald Reagan Medical Center at UCLA, David Geffen School of Medicine at UCLA, 757 Westwood Plaza, Suite 2125, Los Angeles, CA 90095-743730, USA

Tel: +1-310-267-8771, Fax: +1-310-267-3631

E-mail:EdwardLee@mednet.ucla.edu

http://orcid.org/0000-0003-0418-1454 
marily by the high demand and low supply of organ donation. Fewer than $20 \%$ of patients are candidates for resection due to tumor size $(>3 \mathrm{~cm})$, unresectable anatomical locations, undesirable number or distribution of tumors, extrahepatic involvement, and low healthy tissue reserve due to cirrhosis and other co-morbidities. ${ }^{6}$ Unfortunately, the median survival for patients with HCC is less than a year without treatment, and increases greatly with surgical resection or transplantation. However, even in HCC patients who do undergo resection, recurrence rates are as high as $70 \%$ at 5 years $^{7}$, therefore development of more consistent and effective treatment methods for unresectable liver cancer patients is crucial.

There is no clinically proven current standard for treatment for patients with unresectable $\mathrm{HCC}^{7}$ In this paper, we present four different transarterial therapies including TACE with drug-eluting beads (DEB-TACE), transarterial embolization (TAE) or bland em- bolization and radioembolization or SIRT using ${ }^{90} \mathrm{Y}$ microspheres. These techniques are generally accepted as effective palliative treatment and are increasingly being utilized to downstage tumors prior to surgery and to prolong survival. In addition, we plan to briefly discuss recent chemotherapeutic agents including Bevacizumab (Avastin ${ }^{\circledR}$ ) and Panitumumab (Vectibix ${ }^{\circledR}$ ).

\section{cTACE}

In the early 1970's, angiographers first experimented with embolization agents during angiographic procedures to treat liver tumors with palliative effects. ${ }^{8}$ Over the years the technique has evolved to now treat unresectable HCC, colorectal liver metastases, neuroendocrine liver metastases, cholangiocarcinoma, ocular melanoma, and metastatic sarcoma., ${ }^{5,6}$ TACE involves the catheter-

Table 1. Summary of evidence for transarterial chemoembolization (TACE)

\begin{tabular}{|c|c|c|c|}
\hline & Authors & $n$ & Summary \\
\hline \multirow[t]{4}{*}{ TACE (conventional) } & $\begin{array}{l}\text { Solomon, et al." } \\
\text { (1999) }\end{array}$ & 38 & $\begin{array}{l}\text { Cisplatin, doxorubicin, mitomycin-C, ethiodol, polyvinyl alcohol. } \\
\text { Biologic response: 70\% partial, 15\% minor, 15\% stable } \\
\text { Morphologic response: } 36 \% \text { partial, 32\% minor, 32\% stable }\end{array}$ \\
\hline & Lo, et al. ${ }^{12}$ (2002) & 40 & $\begin{array}{l}\text { Cisplatin, lipiodol, gelatin sponge particles vs symptomatic treatment } \\
\text { Increased survival in chemoembolization group } 1 \text { year } 57 \% \text {, } 2 \text { years } 31 \%, 3 \text { years } 26 \% \text { vs } \\
\text { control } 1 \text { year } 32 \% \text {, } 2 \text { years } 11 \%, 3 \text { years } 3 \% \text { (P 0.002) }\end{array}$ \\
\hline & $\begin{array}{l}\text { Marelli, et al. } \\
\text { (2007) }\end{array}$ & 175 & $\begin{array}{l}\text { Meta-analysis of single, double or triple agent transarterial chemotherapies } \\
\text { Objective response } 40+/-20 \% \\
\text { Survival rates at 1,2,3,5 years of } 62+/-20 \%, 42+/-17 \%, 30+/-15 \%, 19+/-16 \% \text {. } \\
\text { Survival time } 18+/-9.5 \text { months }\end{array}$ \\
\hline & $\begin{array}{l}\text { Llovet, et al. }{ }^{14} \\
\text { (2003) }\end{array}$ & 545 & $\begin{array}{l}\text { Meta-analysis of TACE vs tamoxifen } \\
\text { Survival benefit with cisplatin/doxorubicin OR 0.42, 95\% Cl 0.2-0.88). No survival benefit with } \\
\text { embolization alone OR } 0.59,95 \% \mathrm{Cl}, 0.29-1.20) \text {. Tamoxifen showed no antitumoral effect or } \\
\text { survival benefit (OR } 0.64,95 \% \mathrm{Cl} 0.36-1.13, P=0.13 \text { ) }\end{array}$ \\
\hline \multirow[t]{3}{*}{ TACE (doxorubicin) } & $\begin{array}{l}\text { Lammer, et al. } \\
\text { (2010) }\end{array}$ & 212 & $\begin{array}{l}\text { TACE with doxorubicin loaded on drug eluting beads loaded or TACE with doxorubicin oil } \\
\text { emulsion and gelatin sponge. } \\
\text { Higher complete response ( } 27 \% \text { vs } 22 \%) \text {, objective response ( } 52 \% \text { vs } 44 \%) \text {, disease control } \\
(63 \% \text { vs } 42 \%)(P=0.11) \text {. } \\
\text { Significant increase in objective response of patients who received drug eluting beads and } \\
\text { had Child-Pugh B, ECOG 1, bilobar disease and recurrent disease }(P=0.038) \\
\text { Drug eluting beads associated with lower serious liver toxicity }(P<0.001) \text { and less doxorubicin } \\
\text { related side effects ( } P=0.0001) \text {. }\end{array}$ \\
\hline & $\begin{array}{l}\text { Golfieri, et al. }^{20} \\
\text { (2014) }\end{array}$ & 177 & $\begin{array}{l}\text { Doxorubicin loaded drug eluting bead TACE vs conventional TACE } \\
\text { No difference in survival, local or overall tumor response or median time to progression } \\
\text { between the two groups. } \\
\text { Post procedural pain more frequent and severe after CTACE }(P<0.001) \text {. } \\
\text { ECOG, serum albumin and tumor number independently predicted survival }(P<0.05) \text {. }\end{array}$ \\
\hline & $\begin{array}{l}\text { Facciorusso, et } \\
\text { al. }^{21}(2016)\end{array}$ & 676 & $\begin{array}{l}\text { Meta-analysis of transarterial chemoembolization vs bland embolization } \\
\text { No difference in } 1 \text { year, } 2 \text { year or } 3 \text { year survival }(P=0.16,0.18,0.81) \\
\text { No difference in objective response and one year progression free survival }(P=0.36, P=0.40) \text {. } \\
\text { Significant increase in severe toxicity after chemoembolization ( } P=0.01 \text { ). }\end{array}$ \\
\hline
\end{tabular}


Edward Wolfgang Lee, et al.

Recent Advances in transaterial embolotherapy in HCC

based delivery of various chemotherapeutic drugs to the arteries supplying the tumor, combined with the delivery of embolic material for containment and reduction of arterial inflow, which prolongs the duration of contact of the chemotherapeutic agent with the tumor. Hypervascularized tumors are predominantly supplied by the hepatic artery whereas normal liver parenchyma is typically supplied by the portal vein, therefore this method of targeting the hepatic artery allows healthy liver tissue to be spared. ${ }^{5}$

Although various chemotherapeutic agents are used in TACE, the most commonly used single agent is doxorubicin. ${ }^{9}$ A combination of cisplatin, doxorubicin and mitomycin $C$ has been also favorable amongst the interventional radiology community. Ethiodol is used as an emulsifying agent with preferential ability to bind to tumor cells, deliver chemotherapeutic agents, and cause ischemia through embolization and vascular occlusion. A variety of several other embolic materials are also used with TACE, including Gelfoam, microspheres (Embozene ${ }^{\circledR}$ and Embospheres ${ }^{\circledR}$ ), and polyvinyl alcohol (PVA) particles. ${ }^{5}$ Gelfoam is indicated for temporary vascular occlusion where recanalization is desired after a short duration, for example to temporarily occlude a shunt. Microspheres and PVA particles are indicated for more permanent vascular occlusion. The selection and advantage of each embolic agent remain controversial and operator dependent. Overall, embolization allows for up to a two-fold increase in peri-tumoral drug concentration, decreased systemic toxicity, increased tumor destruction and decreased drug resistance via stasis and ischemia. The maintenance of arterial patency is imperative, as multiple sequential treatments of CTACE are commonly performed and may increase patient survival. Tumor size and perfusion status is evaluated on imaging studies every 4 to 12 weeks to evaluate response to treatment. ${ }^{6}$

\section{CTACE FOR HCC}

Despite persuasive clinical results from CTACE, the evidence for clinical efficacy has not yet been well assessed in randomized clinical trials. Numerous studies have been published and multiple clinical trials are being conducted or in process of completion (approximately 191 clinical trials worldwide at the time of publica$\left.\operatorname{tion}^{10}\right)$, however interpretation of the results has been challenging for several reasons. Firstly, the measure of treatment success of CTACE in HCC is attributed to many factors, without standardization to provide uniform comparison of the data among the current studies. Secondly, with the use of numerous staging systems, inclusion criteria and exclusion criteria, there is increased difficulty in comparison of different centers. Interestingly, patient survival is the most commonly cited and relevant outcome measure in studies, despite the short life expectancy of HCC patients.

Aside from the lack of evidence supporting the clinical efficacy of CTACE, it has maintained its status as a robust therapeutic option throughout the years, mainly due to clinical expertise and paucity of good alternatives for unresectable HCC. Prospective non-randomized trials in the United States also show survival data comparable to the latest randomized controlled trials performed in other countries."

A randomized controlled trial performed in 2002 in Hong Kong and demonstrated that CTACE (with cisplatin, lipiodol and gelfoam)-treated patients have significantly better survival than a control group (1 year, $57 \%$ vs. $32 \%$; 2 years, $31 \%$ vs. $11 \% ; 3$ years, $26 \%$ vs. $3 \% .^{12}$ A European study involving 75 patients also showed improved survival of TACE over symptomatic treatment (1 year, $82 \%$ vs. $63 \%$; 2 years, $63 \%$ vs. $27 \%$; 3 years, $29 \%$ vs. $17 \% .^{13}$ The patients enrolled in both these studies were comprised of patients with intermediate tumor stage and preserved liver

Table 2. Summary of evidence of bland transarterial embolization (TAE)

\begin{tabular}{|c|c|c|}
\hline Authors & $n$ & Summary \\
\hline Kluger, et al. ${ }^{23}$ (2014) & 25 & $\begin{array}{l}\text { TACE vs TAE prior to transplantation } \\
\text { TAE patients were less likely than TACE patients to require } 2 \text { procedures }(P=0.04) \\
\text { Explant tumors were completely necrotic for } 36 \% \text { of TAE patients, } 26 \% \text { of TACE patients } \\
3 \text { year survival was higher for TAE }(78 \%) \text { than TACE }(74 \%),(P=0.66) \\
3 \text { year recurrence free survival rates was TAE }(72 \%) \text { and TACE }(68 \%), P=0.83\end{array}$ \\
\hline Massarweh, et al. ${ }^{24}$ (2016) & 405 & $\begin{array}{l}\text { TAE vs TACE } \\
\text { No significant difference in mean survival ( } 20.1 \text { vs } 23.1 \text { months, } P=0.84) \\
\text { No significant difference in risk of death associated with TAE. }\end{array}$ \\
\hline Brown, et al. ${ }^{25}$ (2016) & 101 & $\begin{array}{l}\text { Embolization with microspheres alone vs Doxorubicin-Eluting Microspheres } \\
\text { Similar adverse events in both groups ( } 38 \% \text { vs } 40 \%, P=0.48 \text { ) } \\
\text { No significant difference in RECIST response, median progression free survival and overall survival. }\end{array}$ \\
\hline
\end{tabular}


function (Child-Pugh class A). Despite the difference in patient populations (Asian patients with hepatitis B or European patients with hepatitis $C$ ), similar results from both studies are very encouraging. Furthermore, similarity in survival was found between treated and non-treated patients in the United States through cohort studies. One such study of 38 TACE-treated patients by Solomon, et al. ${ }^{11}$ showed survival rates of 1 year, 60\%; 2 years, $45 \%$; and 3 years, 16\%. A meta-analysis of all cohort studies since 2000_including Western studies_-show comparable survival rates of 1 year, $71 \%$; 2 years, 48\%; 3 years, 34\%. ${ }^{13}$ CTACE shows a significant survival advantage when compared with systemic chemotherapy for HCC patients. The meta-analysis by Llovet, et al. showed an odds ratio of 0.53 in 2-year survival when compared with systemic tamoxifen. ${ }^{14}$
CTACE is typically well-tolerated, however serious complications occur at a mean rate of $5.6 \%$ and include acute liver failure, abscess and sepsis, and gastrointestinal bleeding. ${ }^{15}$ Mortality directly related to CTACE is less than $4 \%$, with 30-day mortality of $1 \%$., 15 The most common complication is a 7-10 day long post-embolization syndrome including nausea, vomiting, fever, and abdominal pain (Table 1). ${ }^{6}$

\section{DEB-TACE}

In order to achieve more sustained levels of chemotherapy concentrated in the tumor, an embolic product, which gradually releases the drug over time, has been developed so-called drug-

Table 3. Summary of evidence for radioembolization $\left.{ }^{90} \mathrm{Y}\right)$

\begin{tabular}{|c|c|c|}
\hline Authors & $n$ & Summary \\
\hline Salem, et al. ${ }^{32}$ (2005) & 43 & $\begin{array}{l}{ }^{90} \text { Y for unresectable hepatocellular carcinoma: safety, tumor reponse and survival in segmental, lobar low } \\
\text { risk and lobar high risk groups, Okuda and Childs-pugh scoring systems. } \\
47 \% \text { objective tumor response based on percent reduction in tumor size } \\
79 \% \text { tumor response based on percent reduction and/or tumor necrosis as a composite measure } \\
\text { Significant difference in survival in segmental ( } 46.5 \text { months), lobar low risk ( } 16.9 \text { months), lobar high risk (11.1 } \\
\text { months) }(P<0.0001) \\
\text { No significant difference in tumor response between segmental, lobar low risk and lobar high risk groups. } \\
\text { Median survival of Okuda I ( } 24.4 \text { months), Okuda II ( } 12.5 \text { months), Childs A ( } 20.5 \text { months), Childs B/C (13.8 } \\
\text { months). }\end{array}$ \\
\hline Lau, et al. ${ }^{36}$ (1998) & 71 & $\begin{array}{l}\text { Intraarterial infusion of }{ }^{90} Y \text { microspheres for non resectable hepatocellular carcinoma } \\
50 \% \text { reduction in tumor volume in } 26.7 \% \text { patients after first treatment } \\
\text { Partial response } 67 \% \text {, complete response } 22 \% \text {, in patients with elevated AFP. } \\
\text { Decrease in serum ferritin by } 34-99 \% \text { after treatment, in pateints without elevated AFP. } \\
\text { Median survival } 9.4 \text { months, range } 1.8-46.4 \text { months }\end{array}$ \\
\hline Kulik, et al. ${ }^{37}$ (2006) & 150 & $\begin{array}{l}{ }^{90} \text { Y for unresectable hepatocellular carcinoma: downstaging to resection, RFA, bridge to transplantation. } \\
56 \% \text { were downstaged from UNOS T3 to T2 after treatment } \\
32 \% \text { were downstaged to target lesions }<3.0 \mathrm{~cm} \\
66 \% \text { were downstaged to UNOS T2, lesion }<3.0 \mathrm{~cm} \text { (RFA candidate) or resection. } \\
50 \% \text { had an objective tumor response by WHO criteria } \\
23 \% \text { were downstaged and underwent OLT after treatment. } \\
1,2 \text { and } 3 \text { year survival was } 84 \%, 54 \% \text { and } 27 \% \text {. } \\
\text { Median survival for entire cohort }=800 \text { days. }\end{array}$ \\
\hline Salem, et al. ${ }^{30}$ (2016) & 179 & $\begin{array}{l}{ }^{90} Y \text { vs conventional TACE } \\
\text { Significantly longer median time to progression in Y90 patients than cTACE patients ( }>26 \text { months, } 6.8 \\
\text { months, } P=0.0012 \text { ) } \\
\text { TACE group had significantly higher diarrhea ( } 21 \% \text { vs } 0 \%, P=0.031 \text { ), hypoalbuminemia ( } 58 \% \text { vs } 4 \%, P<0.001 \text { ). } \\
\text { Similar response to therapy, marked by necrosis in both groups ( } P=0.433 \text { ) } \\
\text { Median survival time, censored to liver transplantation was } 17.7 \text { months for TACE group vs } 18.6 \text { months for } \\
\left.{ }^{90} Y \text { group ( } P=0.99\right)\end{array}$ \\
\hline Lobo, et al. ${ }^{40}$ (2016) & 533 & $\begin{array}{l}\text { Systematic review and meta-analysis of radioembolization (TARE) vs chemoembolization (TACE) } \\
\text { No significant difference in survival up to } 4 \text { years between the two groups }(P=0.567) \\
\text { TACE had more post treatment pain than TARE }(P<0.01) \text {, less subjective fatigue }(P<0.01) \text {. } \\
\text { No difference between the two groups with post treatment nausea, vomiting, fever or other complications. } \\
\text { No significant difference in partial or complete response between the two groups. }\end{array}$ \\
\hline
\end{tabular}


eluting embolic beads. Currently, there are three commercially available, but without FDA indications, DEB-TACE (Oncozene ${ }^{\circledR}$, DC/LC Beads ${ }^{\circledR}$ and QuadraSpheres ${ }^{\circledR}$ ) in the U.S. These are being used for chemoembolization of liver cancer. The beads are loaded with a drug solution, doxorubicin being the most commonly used chemotherapeutic agent so that the drug is "trapped" or "attached" within the beads during delivery. The rate of drug elution (drug release kinetics) from the beads when delivered to the desired site varies based on the osmolarity of the tumor bed, concentration of the drug, and size of the beads. In vivo studies in animal tumor models showed a $400 \%$ increase in intra-tumoral doxorubicin at 72 hours post injection using DEB-TACE when compared with CTACE. ${ }^{16}$ Consequently, tumor necrosis is more profound. ${ }^{16,17}$ Peripheral blood levels of these chemotherapeutic drugs were also found to be significantly lower as compared with CTACE, which should result in reduced systemic toxicity. ${ }^{18}$

A study by Varela, et al. ${ }^{18}$, in 27 Child-Pugh A patients treated with two rounds of DEB-TACE showed preliminary data on survival rates of 1 year, $92.5 \%$ and 2 years, $88.9 \%$. Average drug concentrations in peripheral blood were lower than CTACE, though these values did not reach statistical significance. ${ }^{18}$ This reduced systemic toxicity may allow for even higher doses of intra-tumoral chemotherapy as repeated locoregional treatment is feasible. Contrast uptake on dynamic CT demonstrated a significantly higher tumor response rate after DEB-TACE therapy than CTACE with $44.4 \%$ partial responses, $25.9 \%$ stable disease and a total of $66.6 \%$ objective response. ${ }^{18}$ The PRECISION V study of 212 patients with HCC treated with either doxorubicin loaded DEB-TACE or CTACE, found higher rates of complete response ( $27 \%$ vs $22 \%)$, objective response ( $52 \%$ vs $44 \%$ ) and disease control ( $63 \%$ vs $52 \%$ respectively. ${ }^{19} \mathrm{~A}$ significant increase in objective response $(P=0.038)$ was noted in patients with Child-Pugh B, ECOG 1, bilobar disease and recurrent disease of DEB-TACE compared to CTACE. In a study with 177 patients of which 89 received DEBTACE (doxorubicin coated drug eluting bead TACE) and 88 received CTACE, post procedural pain was more frequent and severe after CTACE $(P<0.001){ }^{20}$ No significant difference was found in the local or overall tumor response, time to progression, 1-year survival or 2-year survival between the two groups. In a single center series of 249 patients with early or intermediate HCC, the objective response rate was significantly higher $(P=0.039)$ with CTACE $(85.3 \%)$ compared to DEB-TACE $(74.8 \%)$, and the median time to progression was longer (17 months vs 11 months). ${ }^{21}$ No significant difference was noted in median survival between the two groups (39 months vs 32 months), however cTACE demon- strated a significant survival advantage in patients with bilobar neoplasia, portal hypertension and elevated alpha-fetoprotein levels.

\section{TAE}

Bland embolization can also be performed without chemotherapy, known as TAE, relying solely on ischemia-induced effects on tumor. TAE without tumoricidal agents may cause ischemia, theoretically triggering peritumoral angiogenesis and paradoxical tumor growth and metastatic spread. ${ }^{22} \mathrm{~A}$ case controlled retrospective study which compared patients who received TACE or TAE found no significant differences in 3 year survival (TAE 78\%, TACE $74 \%, P=0.66$ ), Model for End-Stage Liver Disease score and liver transplant waiting time between the two groups. ${ }^{23}$ TAE patients required less repeat procedures (16\%) compared to TACE patients (40\%). In a nationwide cohort study of 405 patients $^{24}$, of which $7.9 \%$ underwent TAE and the remaining patients received TACE as first line treatment for HCC, no difference in median survival was found (TACE 20.1 versus TAE 23.1 months, logrank $P=0.84)$. In 101 patients with Barcelona Clinic Liver Cancer Stage A $(22 \%)$, or Stage B or C (78\%), of which 51 received TAE with microspheres alone and 50 received DEB-TACE with doxorubicin 150mg, no significant difference was found in RECIST response, adverse events, progression free survival or overall survival (Table 2). ${ }^{25}$

\section{${ }^{90}$ Y RADIOEMBOLIZATION OR SIRT}

Radiation therapy has been used in cancer treatment for more than 100 years since the discovery of the $x$-ray by Roentgen in 1895. However, it is impossible to achieve a tumoricidal radiation dose of greater than $120 \mathrm{~Gy}$ to focal tumor of the liver without severe complications including liver failure and other fatal GI symptoms. ${ }^{26} \mathrm{~A}$ new concept of locoregional radiation treatment has been developed and was introduced in 1963 with the intention of effectively treating tumors while minimizing complications associated with radiation. ${ }^{27}$ More than 5000 patients have been treated with ${ }^{90} \mathrm{Y}$ since it's first medical use in $1956^{28,29}$ and the first ${ }^{90} \mathrm{Y}$ radioembolization treatment was performed in colorectal hepatic metastases in $1964 .^{30}$

Radioembolization or SIRT is an emerging treatment option for unresectable primary HCC and colorectal hepatic metastases. ${ }^{90} \mathrm{Y}$ 
is produced by beta decay and co-exists in equilibrium with its parent isotope Strontium $90\left({ }^{90} \mathrm{Sr}\right)$. It emits characteristic positron ( $\beta$-particle) radiation via beta decay with a half-life of 64.1 hours and penetrability of $2.5 \mathrm{~mm}$ in soft tissue. Just like in TACE, radioembolization is developed with the concept of utilizing the hepatic arterial flow to the tumor bring the treatment to the malignancy. This results in ${ }^{90} \mathrm{Y}$ microspheres being preferentially and focally collected within and close proximity to the tumor. This advantage preserves adjacent normal hepatic tissues which are more preferentially supplied by branches of the portal venous system.

Currently, two radioembolization agents are available globally: SIR-Spheres ${ }^{\circledR}$ and Thera-Spheres ${ }^{\circledR}$. SIR-Spheres (Sirtex Medical, Wilmington, MA, USA), made of resin or polymer beads, are US FDA approved for the transarterial treatment of hepatic metastases from colorectal cancer. SIR-Sphere with a size of 20-60 $\mu \mathrm{m}$ has a higher embolic potential than Thera-Spheres (a size of 25 $35 \mu \mathrm{m})$. Each dose per vial contains 40-80 million microspheres with a maximal dose of up to $3 \mathrm{GBq}$. Thera-Spheres (BTG Medical, Ottawa, Canada), made of insoluble glass, are US FDA HDE (Humanitarian Device Exemption) approved for the transarterial treatment of unresectable HCC. Each dose per vial contains 1.2-8 million microspheres with a maximal dose of $20 \mathrm{GBq}$.

Recent studies have shown that radioembolization is effective in the treatment of unresectable primary HCC and colorectal hepatic metastasis. ${ }^{26,31-35}$ Studies performed in the US done by Kennedy, et al., and Salem, et al. have demonstrated a median survival of 10.5 months $^{35}$ and 12.5 months ${ }^{32}$ respectively, which is comparable to an Australian study with mean survival of 15 months ${ }^{31}$ and 9.4 months in an Asian study. ${ }^{36}$ In addition to survival data, Kulik, et al. have demonstrated potential down-staging of HCC with Thera-Spheres to T2 tumor staging status, which may provide the potential for surgical treatments, including $\mathrm{OLT}^{37} \mathrm{An}$ other important aspect of radioembolization includes the tumoricidal effect of radiombolization which may provide symptomatic improvement of cancer patients due to decreased tumor burden. As with other tumoricidal therapeutic treatments, several side effects have been reported including direct radiation effects and severe gastrointestinal toxicities. ${ }^{38}$ These side effects are likely due to variant or collateral circulation which allows radioembolic material to be deposited in undesired locations.

Comparison of 179 patients with Barcelona Clinic Liver Cancer stage A or B demonstrated a significantly longer median time to progression in patients who received ${ }^{90} Y$ than CTACE ( $>26$ months vs 6.8 months, $P=0.007$ ) and increased diarrhea (21 vs $0 \%$, $P=0.031)$ and hypoalbuminemia (58\% vs $4 \%, P<0.001$ ) was not- ed in the CTACE group compared to the ${ }^{90} \mathrm{Y}$ group. ${ }^{39}$ No difference in the median survival time was found between the two groups. In a large meta-analysis of 553 patients with unresectable HCC, 284 underwent TACE and 269 underwent transaterial radioembolization. ${ }^{40}$ TACE required longer hospital stay $(P<0.01)$ and had more post treatment pain $(P<0.01)$, but less subjective fatigue compared to transarterial radioembolization. No significant difference in survival up to 4 years, post treatment nausea, vomiting, fever, partial or complete response was found between the two groups (Table 3).

Two current clinical trials for SIR-Spheres in the US are currently being conducted..$^{10}$ These randomized clinical trials will provide further insights into re which appears promising in its preliminary results in treating hepatic malignancies.

\section{THE FUTURE OF TRANS-ARTERIAL EMBOLIZA- TION THERAPY}

Trans-arterial embolization therapy has become a widely utilized therapeutic option for patients with advanced hepatic malignancies who cannot be effectively treated with surgical resection or ablative methods. Although Trans-arterial embolization therapy has been shown to be effective in prolonging survival and resulted in tumor response in those patients with advanced diseases, further investigation to better understand its pathophysiology, toxicology/side-effects, immunological responses and genomic and proteomic changes, are crucial to improve efficacy, patient tolerability and survival benefit after Trans-arterial embolization therapy.

Systemic chemotherapeutic treatment of HCC has been shown to have little to no effect on patient survival or palliation. However, implementing newer chemotherapeutic agents, especially targeting angiogenesis, into locoregional chemoembolization may further benefit patient survival and may have synergistic tumoricidal effect when concomitantly used with current agents. These agents include Bevacizumab (Avastin ${ }^{\circledR}$, monoclononal anti-VEGFR antibody), Sorefanib (Nexavar ${ }^{\circledR}$, tyrosine kinase antagonist), Erlotinib (Tarceva ${ }^{\circledR}$, EGFR tyrosine kinase inhibitor), and Panitumumab (Vectibix $^{\circledR}$, monoclononal anti-EGFR antibody). In 2008, the SHARP trial in over 300 patients with advanced HCC has demonstrated the survival benefit of Sorefanib with the median overall survival of 10.7 months compared to the placebo group with 7.9 months $(P<0.001){ }^{41}$

In conclusion, attention should be given to newer technologies 
for early diagnosis of cancer, genetic and subcellular analysis of cancer, monitoring of cancer progression and post-treatment progression which ultimately determines patient survival and the effectiveness of treatments. Modern technologies including microarray gene expression profiling, proteomic data, molecular imaging and newer diagnostic/functional imaging, which will be incorporated with chemoembolization treatment regimens. These technologies should provide extensive and novel information on cellular and molecular level events which dictates the outcome of hepatic malignancy. In addition, we will be able to understand individual differences in treatment response and identify novel and personalized diagnostic and therapeutic regimens for hepatic malignancies.

\section{Authors' contribution}

Lee EW and Khan S equally contributed to this paper with conception and design of the study, literature review and analysis, drafting and critical revision and editing, and final approval of the final version.

\section{Conflicts of Interest}

The authors have no conflicts to disclose.

\section{REFERENCES}

1. Jemal A, Bray F, Center MM, Ferlay J, Ward E, Forman D. Global cancer statistics. CA Cancer J Clin 2011;61:69-90.

2. Mittal S, El-Serag HB. Epidemiology of hepatocellular carcinoma: consider the population. J Clin Gastroenterol 2013;47(Suppl):S2-S6.

3. El-Serag HB, Mason AC. Rising incidence of hepatocellular carcinoma in the United States. N Engl J Med 1999;340:745-750.

4. Lang K, Danchenko N, Gondek K, Shah S, Thompson D. The burden of illness associated with hepatocellular carcinoma in the United States. J Hepatol 2009;50:89-99.

5. Liapi E, Geschwind JF. Transcatheter and ablative therapeutic approaches for solid malignancies. J Clin Oncol 2007;25:978-986.

6. Brown DB, Geschwind JF, Soulen MC, Millward SF, Sacks D. Society of Interventional Radiology position statement on chemoembolization of hepatic malignancies. J Vasc Interv Radiol 2006;17(2 Pt 1):217-223.

7. Imamura H, Matsuyama Y, Tanaka E, Ohkubo T, Hasegawa K, Miyagawa $S$, et al. Risk factors contributing to early and late phase intrahepatic recurrence of hepatocellular carcinoma after hepatectomy. J Hepatol 2003;38:200-207.

8. Reuter SR. The current status of angiography in the evaluation of cancer patients. Cancer 1976;37(1 suppl):532-541.
9. Ono Y, Yoshimasu $T$, Ashikaga $R$, Inoue $M$, Shindou $H$, Fuji $K$, et al. Long-term results of lipiodol-transcatheter arterial embolization with cisplatin or doxorubicin for unresectable hepatocellular carcinoma. Am J Clin Oncol 2000;23:564-568.

10. U.S. National Library of Medicine. ClinicalTrials.gove Website $<$ https://clinicaltrials.gov>. Accessed 2017.07.21.

11. Solomon B, Soulen MC, Baum RA, Haskal ZJ, Shlansky-Goldberg RD, Cope C. Chemoembolization of hepatocellular carcinoma with cisplatin, doxorubicin, mitomycin-C, ethiodol, and polyvinyl alcohol: prospective evaluation of response and survival in a U.S. population. J Vasc Interv Radiol 1999;10:793-798.

12. Lo CM, Ngan H, Tso WK, Liu CL, Lam CM, Poon RT, et al. Randomized controlled trial of transarterial lipiodol chemoembolization for unresectable hepatocellular carcinoma. Hepatology 2002;35:11641171.

13. Marelli L, Stigliano R, Triantos C, Senzolo M, Cholongitas E, Davies $\mathrm{N}$, et al. Transarterial therapy for hepatocellular carcinoma: which technique is more effective? A systematic review of cohort and randomized studies. Cardiovasc Intervent Radiol 2007;30:6-25.

14. Llovet JM, J Bruix. Systematic review of randomized trials for unresectable hepatocellular carcinoma: Chemoembolization improves survival. Hepatology 2003;37:429-442.

15. Cammà C, Schepis F, Orlando A, Albanese M, Shahied L, Trevisani F, et al. Transarterial chemoembolization for unresectable hepatocellular carcinoma: meta-analysis of randomized controlled trials. Radiology 2002;224:47-54.

16. Lewis AL, Gonzalez MV, Lloyd AW, Hall B, Tang Y, Willis SL, et al. DC bead: in vitro characterization of a drug-delivery device for transarterial chemoembolization. J Vasc Interv Radiol 2006;17(2 Pt 1):335342.

17. Lewis AL, Taylor RR, Hall B, Gonzalez MV, Willis SL, Stratford PW. Pharmacokinetic and safety study of doxorubicin-eluting beads in a porcine model of hepatic arterial embolization. J Vasc Interv Radiol 2006;17:1335-1343.

18. Varela $M$, Real MI, Burrel $M$, Forner $A$, Sala $M$, Brunet $M$, et al. Chemoembolization of hepatocellular carcinoma with drug eluting beads: efficacy and doxorubicin pharmacokinetics. J Hepato 2007;46:474-481.

19. Lammer J, Malagari K, Vogl T, Pilleul F, Denys A, Watkinson A, et al. Prospective randomized study of doxorubicin-eluting-bead embolization in the treatment of hepatocellular carcinoma: results of the PRECISION V study. Cardiovasc Intervent Radiol 2010;33:41-52.

20. Golfieri R, Giampalma E, Renzulli M, Cioni R, Bargellini I, Bartolozzi $C$, et al. Randomised controlled trial of doxorubicin-eluting beads vs conventional chemoembolisation for hepatocellular carcinoma. Br J Cancer 2014;111:255-264.

21. Facciorusso A, Di Maso M, Muscatiello N. Drug-eluting beads versus conventional chemoembolization for the treatment of unre- 
sectable hepatocellular carcinoma: A meta-analysis. Dig Liver Dis 2016:48:571-577.

22. Chaudary N, Hill RP. Hypoxia and metastasis. Clin Cancer Res 2007:13:1947-1949.

23. Kluger MD, Halazun KJ, Barroso RT, Fox AN, Olsen SK, Madoff DC, et al. Bland embolization versus chemoembolization of hepatocellular carcinoma before transplantation. Liver Transpl 2014;20:536543.

24. Massarweh NN, Davila JA, El-Serag HB, Duan Z, Temple S, May S, et al. Transarterial bland versus chemoembolization for hepatocellular carcinoma: rethinking a gold standard. J Surg Res 2016;200:552559.

25. Brown KT, Do RK, Gonen M, Covey AM, Getrajdman GI, Sofocleous $C T$, et al. Randomized trial of hepatic artery embolization for hepatocellular carcinoma using doxorubicin-eluting microspheres compared with embolization with microspheres alone. J Clin Oncol 2016;34:2046-2053.

26. Gulec SA, Fong Y. Yttrium 90 microsphere selective internal radiation treatment of hepatic colorectal metastases. Arch Surg 2007;142:675-682.

27. Lafave JW, Grotenhuis I, Kim YS, Maclean LD, Perry JF Jr. Y90tagged microspheres in adjuvant tumor therapy. Surgery 1963;53:778-783.

28. Francois PE, Mallard JR, McKinnell A. Seeds of pure beta-ray emitter (yttrium-90) for radiation hypophysectomy. Nature 1956;178:12401241.

29. Thullen A. [Radiotherapy of inflammatory processes of the nasopharynx and Eustachian tube with a beta-ray emitter of strontium 90-yttrium 90 isotope.]. Strahlentherapie 1956; Sonderbd 35:129133.

30. Ariel IM, Pack GT. Treatment of inoperable cancer of the liver by intra-arterial radioactive isotopes and chemotherapy. Cancer 1967;20:793-804.

31. Gray B, Van Hazel G, Hope M, Burton M, Moroz P, Anderson J, et al. Randomised trial of SIR-Spheres plus chemotherapy vs. chemotherapy alone for treating patients with liver metastases from primary large bowel cancer. Ann Oncol 2001;12:1711-1120.

32. Salem R, Lewandowski RJ, Atassi B, Gordon SC, Gates VL, Barakat $O$, et al. Treatment of unresectable hepatocellular carcinoma with use of $90 \mathrm{Y}$ microspheres (TheraSphere): safety, tumor response, and survival. J Vasc Interv Radiol 2005;16:1627-1639.

33. Sharma RA, Van Hazel GA, Morgan B, Berry DP, Blanshard K, Price $D$, et al. Radioembolization of liver metastases from colorectal cancer using yttrium-90 microspheres with concomitant systemic oxaliplatin, fluorouracil, and leucovorin chemotherapy. J Clin Oncol 2007;25:1099-1106.

34. Van Hazel G, Blackwell A, Anderson J, Price D, Moroz P, Bower G, et al. Randomised phase 2 trial of SIR-Spheres plus fluorouracil/leucovorin chemotherapy versus fluorouraci//leucovorin chemotherapy alone in advanced colorectal cancer. J Surg Oncol 2004;88:78-85.

35. Kennedy AS, Coldwell D, Nutting C, Murthy R, Wertman DE Jr, Loehr $S P$, et al. Resin 90Y-microsphere brachytherapy for unresectable colorectal liver metastases: modern USA experience. Int J Radiat Oncol Biol Phys 2006;65:412-425.

36. Lau WY, Ho S, Leung TW, Chan M, Ho R, Johnson PJ, et al. Selective internal radiation therapy for nonresectable hepatocellular carcinoma with intraarterial infusion of 90yttrium microspheres. Int J Radiat Oncol Biol Phys 1998:40:583-592.

37. Kulik LM, Atassi B, van Holsbeeck L, Souman T, Lewandowski RJ, Mulcahy MF, et al. Yttrium-90 microspheres (TheraSphere) treatment of unresectable hepatocellular carcinoma: downstaging to resection, RFA and bridge to transplantation. J Surg Oncol 2006;94:572-586.

38. Murthy R, Brown DB, Salem R, Meranze SG, Coldwell DM, Krishnan S, et al. Gastrointestinal complications associated with hepatic arterial Yttrium-90 microsphere therapy. J Vasc Interv Radiol 2007;18:553561; quiz 562.

39. Salem R, Gordon AC, Mouli S, Hickey R, Kallini J, Gabr A, et al. Y 90 radioembolization significantly prolongs time to progression compared with chemoembolization in patients with hepatocellular carcinoma. Gastroenterology 2016;151:1155-1163. e2.

40. Lobo L, Yakoub D, Picado O, Ripat C, Pendola F, Sharma R, et al. Unresectable hepatocellular carcinoma: radioembolization versus chemoembolization: a systematic review and meta-analysis. Cardiovasc Intervent Radiol 2016;39:1580-1588.

41. Llovet JM, Ricci S, Mazzaferro V, Hilgard P, Gane E, Blanc JF, et al. Sorafenib in advanced hepatocellular carcinoma. N Engl J Med 2008;359:378-390. 